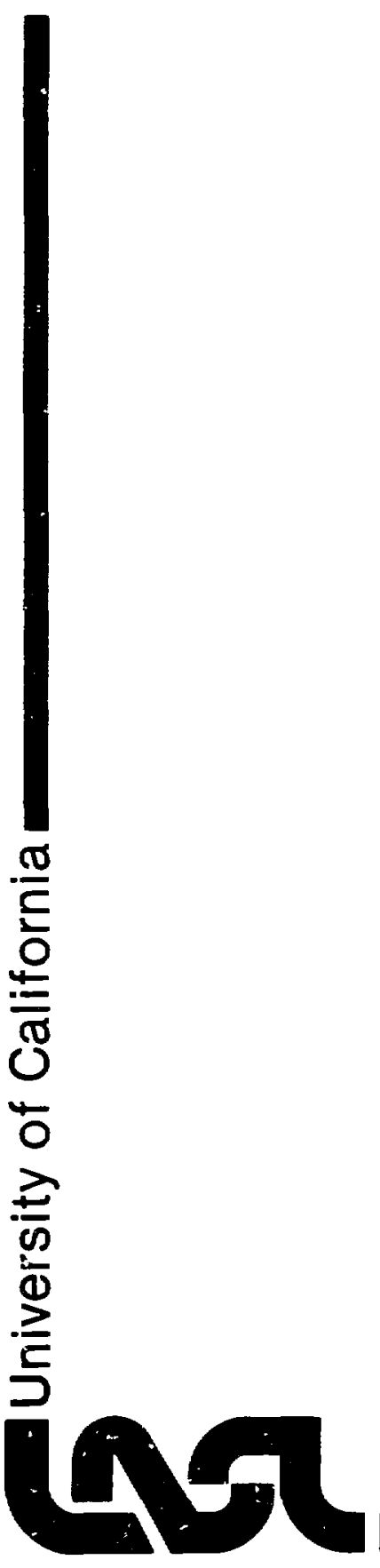

Nondestructive Measurement of Spent Fuel Assemblies at the Tokai Reprocessing and Storage Facility 
LA-80IS-MS

Informal Report

(ISPO-44)

UC-83 (Base Technology)

Issued: December 1979

\title{
Nondestructive Measurement of
}

\section{Spent Fuel Assemblies at the}

\section{Tokai Reprocessing and Storage Facility}

\author{
J. R. Phillips \\ G. E. Bosler \\ J. K. Halbig \\ D. M. Lee
}
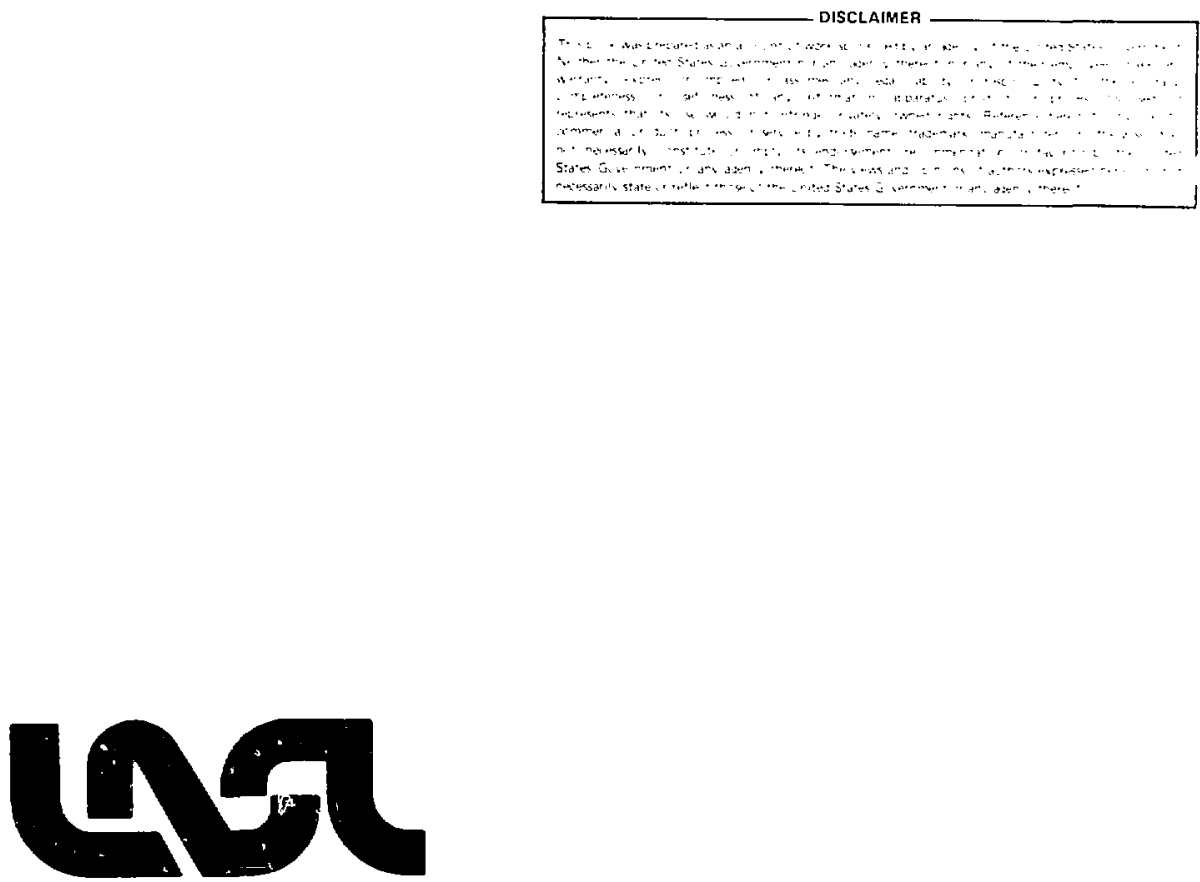
NONDESTRUCTIVE MEASUREMENT OF SPENT FUEL ASSEMBLIES

AT THE TOKAI REPROCESSING AND STORAGE FACILITY

by

J. R. Phillips, G. E. Bosler, J. K. Halbig, and D. M. Lee

\section{ABSTRACT}

Nondestructive verification of irradiated fuel assemblies is an integral part of any safeguards system for a reprocessirg facility. Available techniques are discussed with respect to the level of verification provided by each. A combination of high-resolutioil gamma spectrometry, neutron detectors, and gross gamma activity profile monitors provide a maximum amount of information in a minimum amount of time.

\section{INTRODUCTION}

The Tokai fuel reprocessing facility can reprocess 0.7 metric tons of uranium per day. It ras designed to reprocess Zircaloy or stainless steel clad, low-enriched uranium light water reactor (LWR) fuel and to produce uranium trioxide and plutonium nitrate solution as the final products.

The United States Government shares an international commitment to ensure effective International Atomic Energy Agency (IAEA) safeguards for protection of reactor spent fuel at reprocessing facilities. As a result of this commitment, the U.S., Japan, and France, in cooperation with the IAEA, have agreed to investigate the improvement of safeguards techniques as applied to the PNC Tokai-Mura reprucessing facility. This program consists of 13 tasks, as described in the plan for the Tokai Advanced Safeguards Technology Exercise (TASTEX). I

This report addresses TASTEX task T-B: "Collection and Analysis of Gamma Spectra of Irradiated Fuel Assemblies Measured at the Storage Pond." 1 IAEA inspectors must verify independently the declared nuclear material content of spent fuel assemblies in order to verify receipts and to enable the periodic verification of the inventory in the storage pond. 
Safeguarding the fuel reprocessing facility consists of three internationally agreed upon approaches: containment, surveillance, and material accountancy. The facility is divided into three material balance areas (MBAs). ${ }^{2}$

(1) MBA-1 is the shipper-receiver difference area consisting of the fuel receiving and storage area through the input accountability vessel.

(2) MBA-2 inciudes the chemical process area, waste treatment area, analytical laboratory, and the operation testing laboratory (UTL).

(3) MBA-3 consists of the plutonium product storage vessels and the uranium product storage area.

A strategic safeguards point is the accountability measurement in the fuel receiving and storage area $(M B A-1)$. Without a measurement at this point, accountability is based on uncertain values provided by the reactor operator.

Implementation of IAEA safeguards at the reprocessing facility must be based on five steps: (1) verification of the declared information supplied by the facility operator; (2) measurements at strategic points to maintain continuity of knowledge; (3) periodic closing of material balances and rerification; (4) independent verification by the IAEA based on istatistical sampling procedures; and (5) containment and surveillance. ${ }^{3}$ The problems associated with containment and surveillance have been addressed by Sandia Laboratories in another TASTEX task. 4

Nondestructive techniques are an integral part of each of the first four steps. These techniques are usually separated into two types of measurements; qualitative or attribute measurements, which indicate that the irradiated fuel material contains the correct radioactive signatures; and quantitative or variable measurements, which relate to specific characteristics of the irradiated material, i.e., burnup or fissile content. 5

Qualitative measurements may include the Cerenkov light, ${ }^{6}$ gross gamma, ${ }^{7}$ or neutron emission from the irradiated fuel materials. 8,9 Each measurement has demonstrated applicability to qualitative verirication. Also, the gammaray spectra emitted from a fuel assembly ray be inspected visualiy to ensure that the appropriate mixture of fission products is present.

Quantitative measurements are much more difficult--in fact, the only proven technique is the use of high-resolution gamma-ray spectrometry (HRGS). ${ }^{9-11}$ This technique combined with passive neutron measurements may provide the verification required by the IAEA to safeguard the fuel receiving and storage 
area. At present, the remaining fissile content of irradiated fuel assemblies cannot be measured dirjetly, so these indirect techniques are applied and then correlated to the fisisile content.

Nondestructive techniques for verification of accounting by the IAEA are of primary importance, but they are also important to the facility operator because they ensure efficient and economic operation of the facility. When ownership of the fissile material is to be transferred from the reactor operator to the reprocessing facility, shipper-receiver differences could be resolved on receipt of the material instead of after analysis of the dissolver solution. This would also permit the facility operator to mix fuels from different utilities to obtain specific plutonium and uranium isotopic compositions in the product materials.

Information supplied by nondestructive measurements can also be used to augment in-plant instrumentation for criticality control. The facility operator would benefit from the nondestructive analysis of fuel assemblies as they are received in the storage area, as well as from a rapid verification of the assemblies before the transfer to the mechanical shearing cell.

This report addresses the problems associated with measuring irradiated fuel assemblies and applying proven nondestructive techniques to verify operator-declared information. This report is not restricted to the analysis of HRGS techniques, but includes passive neutrons, Cerenkov, and gross gamma measurement techniques. The complexity of the nondestructive analysis system depends on the specific level of verification required. In particular, the applicability of an HRGS system in conjunction with passive neutron and gamma profile measurements is evaluated.

\section{SPENT FUEL RECEIVING AND STORAGE AREA}

\section{A. Physical Plant}

The Tokai-Mura spent. fuel receiving and storage facility is designed to receive irradiated LWR fuel assemblies with average exposures of $28000 \mathrm{MWD} / \mathrm{MTU}$ and cooling times of at least 120 days. $^{2}$ Shipping casks with 12 boiling water reactor (BWR) or 4 pressurized water reactor (PWR) assemblies ar transported to the facility via truck. After decontamination, the cask is transferred to the unloading pool. Then, the fuel assemblies are put into sealed containers and stored in baskets in the spent fuel storage pool. 
Two schematics of the spent fuel receiving and storage area are shown in Figs. 1 and 2 from the Sandia Laboratories report for TASTEX task A. ${ }^{3}$ The shipping cask is removed from the truck by a 110-ton overhead bridge crane that runs the length of the pool and crane hall. This hall is apprrimately $48 \mathrm{~m}$ long, $14 \mathrm{~m}$ wide, and $14 \mathrm{~m}$ high.

The cask decontamination room is approximately $8 \mathrm{~m}$ square and $10 \mathrm{~m}$ deep and is located below the floor level. A movable hatch covers the decontamination room when shipping casks are not being unloaded. The cask unloading pool is approximately 6 by $12 \mathrm{~m}$ with three different depths to accommodate unloading the shipping casks. This is the only place where the fuel assemblies are isolated and available for nondestructive examinations, except when they are being

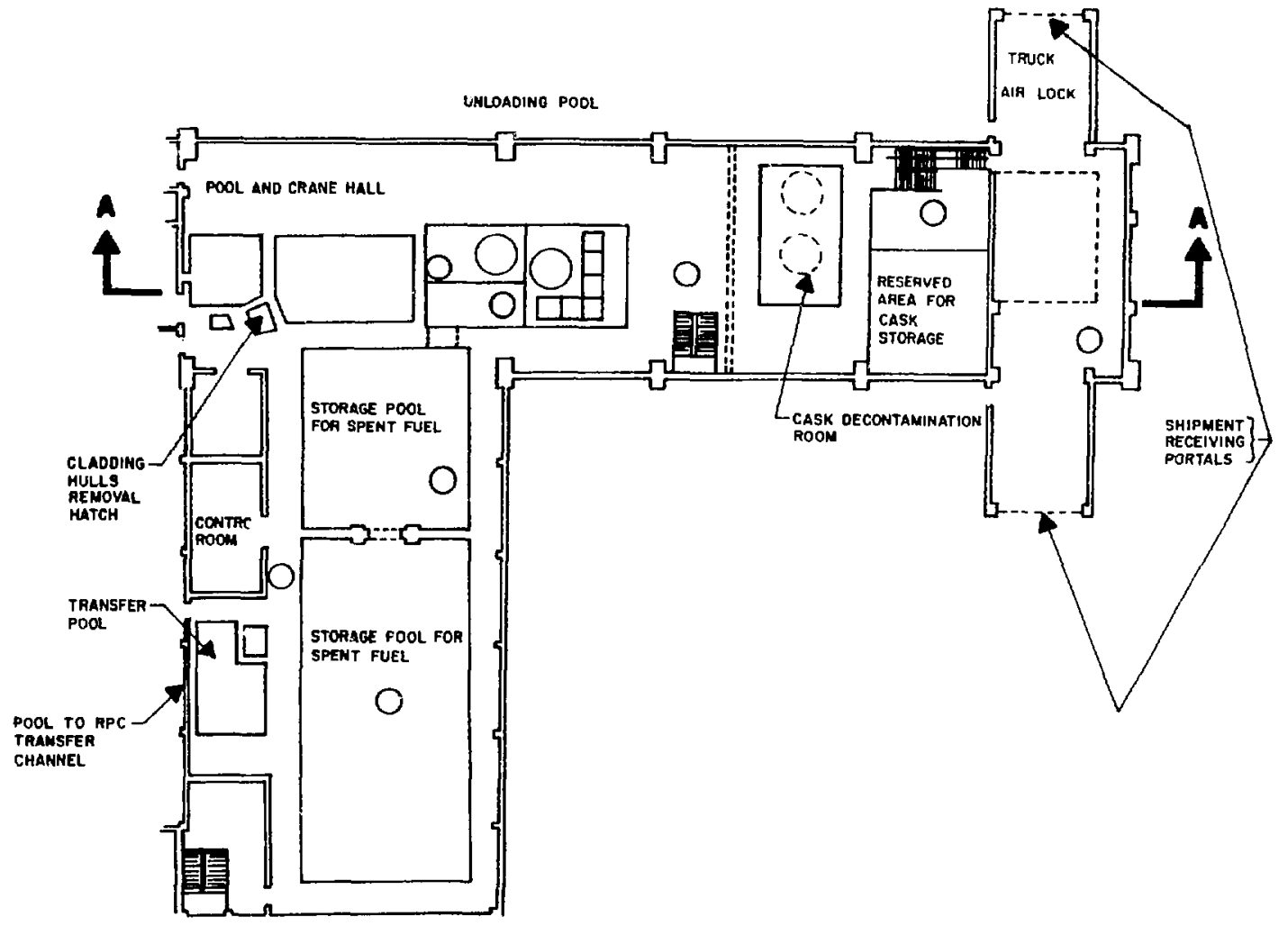

Fig. 1.

Spent fuel receiving and storage area of Tokai-Mura reprocessing facility. 


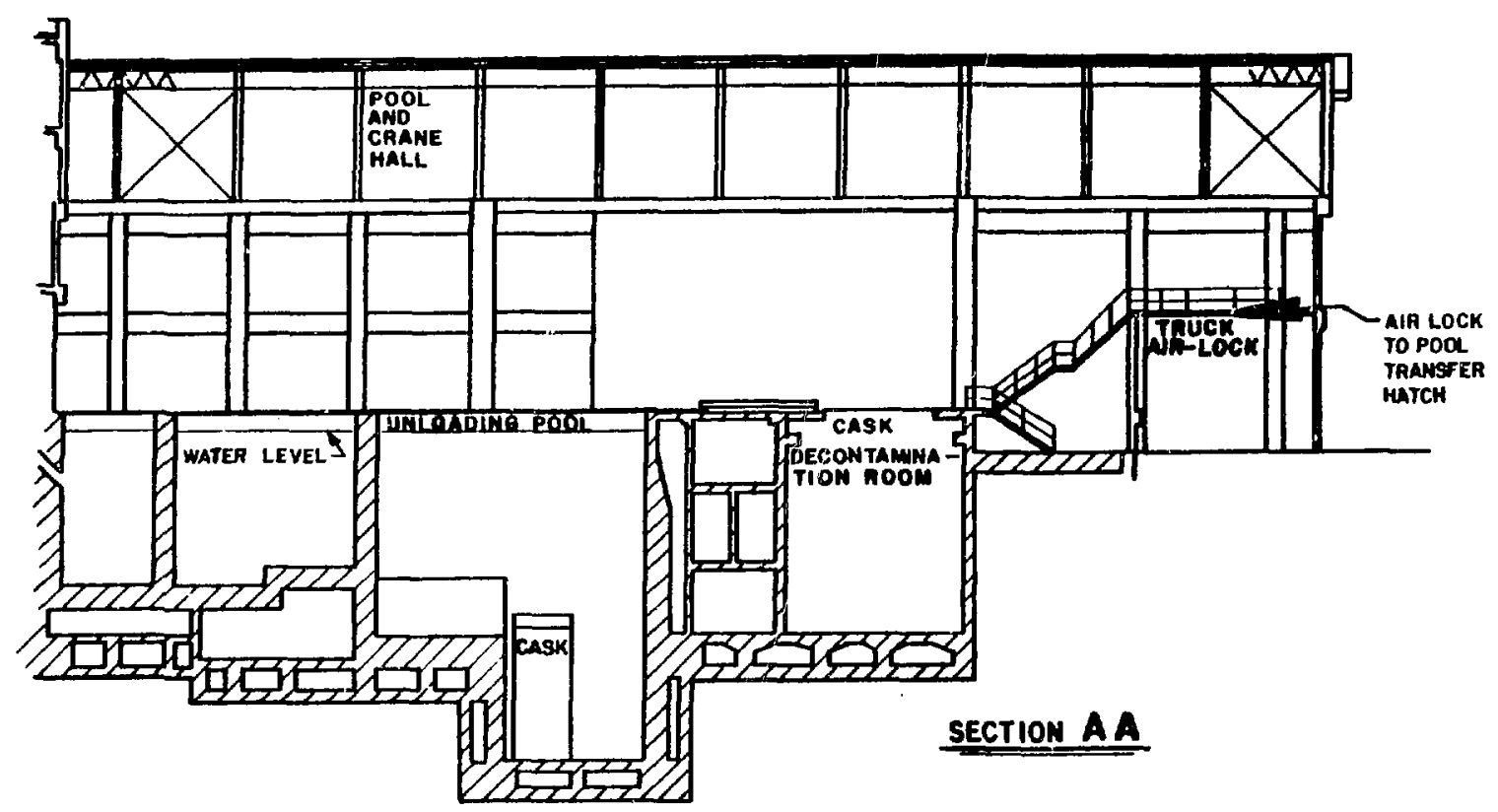

Fig. 2.

Spent fuel receiving area elevation.

transferred to the mechanical shearing cell. Because of severe space limitations, examination apparatus must be designed to minimize any effect on the required unloading operations.

The storage pool for spent fuel actually consists of two pools. The first, approximately 10 by $11 \mathrm{~m}$, is connected to the cask unloading pool by an underwater portal. When a fuel transfer is not taking place, a door separates the unloading pooi and the storage pool. 4 The second storage pool, approximately 10 by $21 \mathrm{r}$, is connected to the first by a 2-m-wide transfer channel.

The second storage pool is also connected to the transfer pool by an underwater portal with an isolating door, like the unloading pool. Fuel is unloaded from the storage basket in the transfer pool to a conveyor that moves it to the mechanical shearing cell through an underwater transfer tunnel.

B. Operations 4

The three basic operations in the spent fuel receiving and storage facility are (1) to unload and decontaminate shipping casks, (2) to remove fuel assemblies from the casks and place them in storage, and (3) to transfer the fuel assemblies to the reprocessing facility. 
The shipping cask is placed in the decontamination room where it is washed and monitored. This requires a minimum of 2 hours, but can require many hours if the cask is contaminated. After decontamination, the cask is moved to the proper shelf in the unloading pool.

Individual fuel assemblies are removed from the shipping cask and are placed in the fuel storage basket. This is the first time that individual fuel assemblies are available for examination at the reprocessing facility. This is a key measurement point because verification of information declared by the reactor facility operator must be completed to provide effective facility safeguards. Declared information is the material input to MBA-1 and these estimates of fissionable material can have large uncertainties. 2 A general description of the calculational techniques available to the reactor operators for determining burnup and fissile content of fuel assemblies is presented in the Appendix.

The fuel assemblies are put in stainless steel storage containers that seal the fuel inside to prevent contamination of the storage pool in case of a leaking fuel rod. When the unloading pool is decontaminated, the door to the stor:age pool is opened and the basket is placed on a shuttle cart, which transfers the basket to the storage pool.

Normally, stored spent fuel assemblies are moved from the storage pool to the transfer pool and then to the reprocessing facility. During this process, individual fuel assemblies are removed from the storage basket and placed horizontally onto a conveyor. The conveyor moves the fuel assembly through the transfer tunnel to the mechanical shearing cell. If the storage area becomes a separate MBA, then the transfer of fuel assemblies to the mechanical cell must be verified.

Individual fuel assemblies are isolated only twice in the fuel receiving and storage facility: (1) when the shipping container is unloaded, and (2) when the assemblies are transferred to the mechanical shearing cell: they are stored in relatively inaccessible baskets the rest of the time. Theoretically, examination time available in the unloading pool is approximately 8 hours for one fuel shipment ( 12 BWR assemblies or 4 PWR assemblies) to minimize problems associated with "leaking" assemblies. 12,13 Actual examination time per assembly is less than $30 \mathrm{~min}$ because the fuel transfer operation is included in the 8-hour period. 
III. VERIFICATION OF OPERATOR-DECLARED VALUES

A. Qualitative or Attribute Measurements

Qualitative or attribute measurements verify that the fuel assembly contains irradiated fuel materials and that a counterfeit assembly has not been substituted. Measurable characteristics of spent fuel assemblies include physical attributes and gross radiations from primary sources like fission products and transuranic isotopes, and from secondary sources that are a result of the interaction of the primary radiations with the surrounding material (Cerenkov light).

1. Physical Characteristics. Irradiated fuel assemblies are discrete units, suitable to item counting, and usually have a unique identification number permanently attached to the supporting structure. In addition, irradiation exposure changes the appearance and color of the assembly. The surface of an individual fuel rod is often covered by a thin layer of corrosion deposits and rub marks where the deposits have been removed. ${ }^{14}$ The colors of rods in the same assembly may vary from shiny gold and brown to reddish brown or dull gray. A visual inspection can provide a low level of verification without using any equipment.

2. Gross Radiation. As the result of the fission process, irradiated fuel issemblies contain radioactive fission product and transuranic isotopes. The gross gamma dose rate at the surface of an LWR assembly with 20-30 000 MWD/MTU burnup can reach levels of $10^{4}-10^{5} \mathrm{R} / \mathrm{h}$. Neutron flux from a fuel assembly can vary from 10000 to $100000 \mathrm{n} / \mathrm{cm}^{2} / \mathrm{s}$, depending upon the measurement environment. In air, the neutron flux is the lower value, ${ }^{15}$ and in water, the higher value. 8 Detection of gamma and neutron radiation provides a higher level of verification of irradiated fuel after visual inspection.

Many NDA techniques exist to measure radiation levels from spent fuel assemblies, including the use of ion chambers, $B e(\gamma, n)$ detectors, fission chambers, solid-state track recorders, a Cerenkov glow detection system, and cadmium telluride detectors. All gamma-ray and neutron signatures of a fuel assembly depend on cooling time, burnup, and irradiation history.

a. Ionization Chambers can be constructed in many configurations with wide ranges of sensitivity, and the use of ion chambers in radiation dosimetry is well understood and extremely reliable. Operating the ion chamber in the current mode, the measurement times are extremely short, typically, a few seconds. An ionization chamber is sensitive to all gamma rays interacting in 
the gaseous volume (and walls), and therefore, sannot discriminate among various gamma rays of selected fission products. The response after short cooling times $(<2 \mathrm{yr})$ reflects the very recent burnup since short-lived gamma-emitting fission products $\left({ }^{140} \mathrm{Ba}-\mathrm{La},{ }^{95} \mathrm{Zr}-\mathrm{Nb}\right)$ dominate at that time. For longer cooling times, the response reflects the integrated burnup since the longer lired isotopes are then dominant.

b. The $\operatorname{Be}(\gamma, n)$ Detector (Fig. 3) is a small fission chamber surrounded by a polyethylene annulus and a beryllium sleeve. It detects fission product gamma rays of energies greater than the 1660-key threshold through the photoneutron reaction,

$$
\begin{gathered}
\gamma+{ }^{9} \mathrm{Be} \rightarrow{ }^{8} \mathrm{Be}+\mathrm{n}-1660 \mathrm{keV} . \\
\llcorner \\
\longrightarrow 2^{4} \mathrm{He}
\end{gathered}
$$

The neutrons released in this reaction are first moderated in the polyethylene and then detected in the fission chamber. The primary gamma ray above the $1660-\mathrm{keV}$ threshold is the $2186-\mathrm{keV}$ gamma ray of the ${ }^{144} \mathrm{Pr}$ (half-life $=17.3 \mathrm{~min}$ ), which is in secular equilibrium with its fission product parent, ${ }^{144} \mathrm{Ce}$ (half-life = 284.5 days $)$. The $\operatorname{Be}(\gamma, n)$ measurement reflects the more recent irradiation exposure ( $3 \mathrm{yr}$ or less) of the fuel assembly. Because this detector relies on pulse counting, the measurement time depends mostly on the statistical precision desired. To obtain $2 \%$ statistics for a typical fuel assembly with approximately

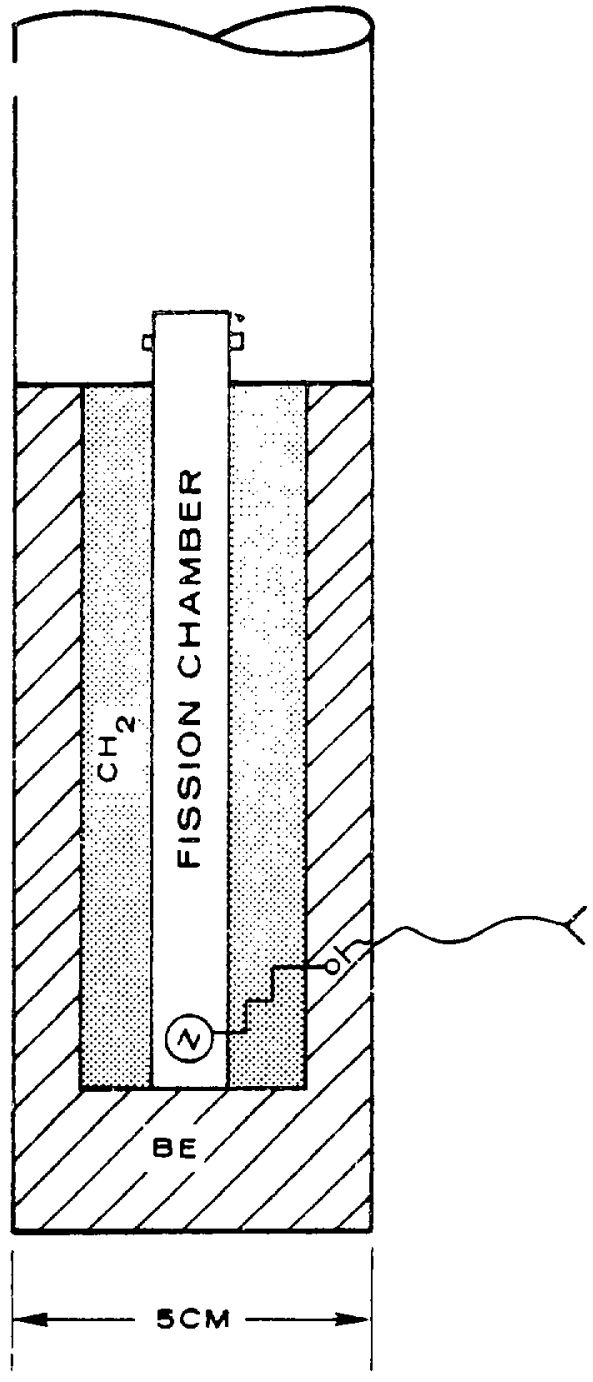

Fig. 3.

$\operatorname{Be}(\gamma, \mathrm{n})$ detector for measuring gamma rays with energies $>1660 \mathrm{keV}$. 
25000 MWD/MTU burnup and 2- to 3-yr cooling time, count times of approximately 5 min would be required for the detector shown in Fig. 3. The principal advantage of this detector is that it is only sensitive to a direct fission product. c. Fission Chambers have long been used for detecting neutrons in the presence of high-gamma-radiation fields. Neutron measurement is a higher level of spent fuel verification because neutrons are produced from the spontaneous fissioning of the even-numbered isotopes of plutonium and curium and from the $(\alpha, n)$ reactions in the oxide material. Although a gross neutron measurement does not differentiate the transuranic elements, the measurement is less subject to self-absorption in the fuel assembly than the gamma-ray measurement. Therefore, the measurement can be used to verify the presence of transuranic material in the inner rods, as well as in the outer rods, of the fuel assembly. The measurement times for fission chambers are typically 10-15 min, and couriting statistics are the deciding factor.

d. Solid-State Track Recorders (SSTR) can be used to measure the neutron flux of an irradiated fuel assembly. ${ }^{15}$ SSTR neutron dosimeters are inexpensive and relatively easy to use; however, exposure times range from several hours to several days, depending on the source strength and the desired precision of the measurement.

e. The Cerenkov Glow Technique is based on measuring the intensity of the Cerenkov glow resulting from the interaction of the radiation from fuel assemblies with the cooling water. ${ }^{6}$ Because water has very smali attenuation coefficients for visible and near-ultraviolet light, the measurement of the Cerenkov glow can be made from above the surface of the water, eliminating the introduction of equipment into the pool. In its simplest application a handheld night-vision camera can be used. One disadvantage of this technique is that light from other sources must be eliminated.

f. Cadmium Telluride Detectors can be used to measure the gamma radiations emitted from irradiated fuel assemblies. ${ }^{5}$ Because only small detectors with subsequent low efficiencies for high-energy gamma rays (> $600 \mathrm{keV}$ ) are available, their applicability in spent fuel examinations is limited.

3. Axial Profiles. Measurement of the axial activity profile of spent fuel assemblies can verify the integrity of the fuel assembly by detelmining that the assembly is radioactive for its entire length, that the activity profile is typical for that type of assembly, and that the absolute activity is similar to that of other assemblies of the same type, cooling time, burnup, and irradiation history. 
Among the many ways to measure the axial activity profile are HRGS, fission chamber, $\operatorname{Be}(\gamma, n)$, ion chamber, and Cerenkov measurements. The HRGS and $\operatorname{Be}(\gamma, n)$ measurements can be related to specific fission product gama rays, whereas the ion chambrr and Cerenkov measurements are nonspecific and can only measure the gross gamma-ray activity profile. The ${ }^{137}$ Cs activity profile is often assumed to represent the autual burnup profile for the BWR and PWR assemblies. Profile measurements with the $\mathrm{Be}(\gamma, n)$ detector have been shown to be in good agreement with ${ }^{137}$ Cs activity profiles. ?

Gross gama activity profiles obtained from the ion chamber have the same shape as the ${ }^{137}$ Cs activity profile, ${ }^{7}$ but care must be taken in extending these conclusions to all fuel assemblies. Because gross gamma activity measurements are sensitive to ali gama rays and different fission product activities dominate at various cooline times, the gross gamma activity profile can change with cooling time. For example, for short cooling times, the short-lived isotopes $140 \mathrm{Ba}-\mathrm{La}$ and $95 \mathrm{Zr}-\mathrm{Nb}$ can dominate (less than $2 \mathrm{yr}$ ), whereas at longer cooling times, ${ }^{10} \mathrm{KL}-\mathrm{Rh},{ }^{137} \mathrm{Cs},{ }^{134} \mathrm{Cs}$, and ${ }^{154} \mathrm{Eu}$ dominate. Therefore, the gamma activity profile measured at short cooling times reflects the very recent burnup or power proilile, ${ }^{16,17}$ and at long cooling times, the gamma activity profile corresponds to the integrated burnup or power profile. If the end-of-cycle power profile is different from the integrated power profile, as can be the case in a BhR reactor, the gamma activity profile measured at short cooling times can differ somewhat froc the profile at longer cooling times. Such differences are minimized for PWR reactors because of the relatively uniform burnup profiles. The Cerenkov glow technique should provide similar resulis without using equipment in the storage pool. Cadmium telluride detectors can also be used to measure the gamma activity as a function of axial position. However, because the detectors can become saturated in the high-gamma-ray environments arjund fuel assemblies, they require an excessive amount of shielding. Also, some problems remain with respect to their long-term reliability under these operating conditions.

Axial profiles measured with neutron detectors are in good agreement with cire ${ }^{137}$ Cs profiles measured with HRGS. ${ }^{8}$ The neutron rate appears to be a nonlinear function of burnup with an empirical power relationship being selected. Unlike the axial gamma measurements that relate the fission product profile to the burnup profile, the neutron measurements relate the axial profile of the transuranic isotnpes to the burnup profile. 
All spent fuel profile measuring systems in use rely on mechanical scanning systems. These systems either move the fuel assembly past the detector or move the detector past the fuel assembly. In general, it takes 30-90 min to measure one assembly by mechanical scanning in conjunction with pulse counting methods [HRGS, fission, $B e(Y, n)]$. Although mechanical scanning systems are successful, the requirement of fuel assembly or detector movement is a majo: drawback to axial profile measurements as applied to safeguards and plant control.

Recently, a multielement system was designed at LASL to eliminate the mechanical scanning system, and it may reduce the measurement times, including gama-ray spectra and neutron measurements, to less than 10 min. This system uses multiple ion chamber elements in one long detector, so that all measurement points on the profile are taken simultaneously rather than sequentially, as is the case with mechanical scanning.

The multielement profile detector can have 15 to 64 identical ion chamber elements equally spaced along the axis of the fuel assembly. ${ }^{18}$ They are in a waterproof enclosure and the signal from each element is transmitted through a waterproof cable to multiplexing electronics located away fron the pool side. A prototype constructed for evaluation of Materials Testing Reactor (MTR) fuel is shown in Fig. 4. This device can record the gamma profile on a cassette, teletype, or other similar recording device in less than $10 \mathrm{~s}$.

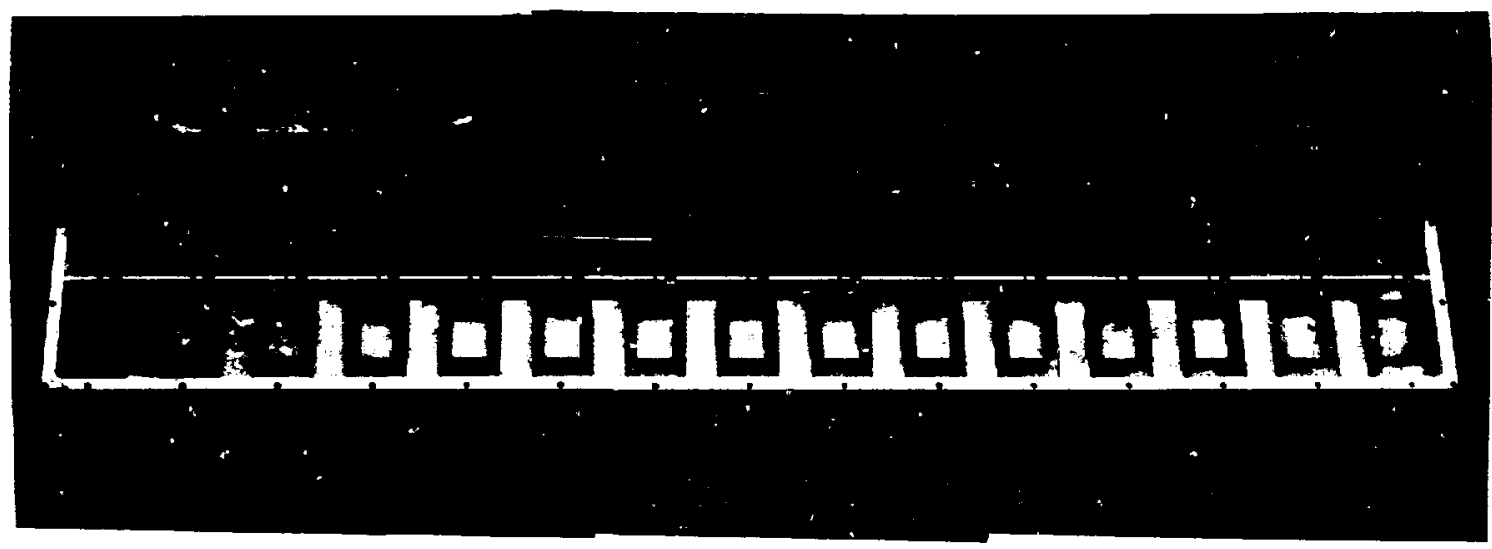

Fig. 4.

Multielement ion chamber for obtaining the axial gross gamma profiles of irradiated fuel elements. 
4. Spectral Identification or Fission Products. Of the more than 800 fission products of irradiated fuel materials, only a few can be measured nondestructively using HRGS. Table I lists those measurable fission product isotopes that have half-lives greater than 30 days. ${ }^{19-21}$

Limits can be placed on the time since discharge by identifying the fission products preseni. If the easily identifiable set of three peaks from ${ }^{95} \mathrm{Zr}-{ }^{95} \mathrm{Nb}$ at 724,757 , and $766 \mathrm{keV}$ are not present, the cooling time is probably greater than 3 years, whereas oider fuel assemblies (approximately 10 years) would have principally ${ }^{134} \mathrm{Cs},{ }^{154} \mathrm{Eu}$, and ${ }^{137} \mathrm{Cs}$ activities in the spectra. A quantitative measurement of total irradiation exposure (burnup) is more difficult because absolute values for specific isotopes must be measured.

Verification of an approximately correct mixture of fission products is a quick technique to ensure that a counterfeit assembly has not been substituted.

TABLE I

MEASURABLE FISSION PRODUCTS IN LWR FUEL ASSEMBLIES

\begin{tabular}{|c|c|c|}
\hline Isotope & Half-life 19 & Principal Gamma Rays (keV) 19-21 \\
\hline $95 \mathrm{Nb}$ & $34.97 \pm 0.03$ days & $765.8(99.82 \%)^{a}$ \\
\hline${ }^{103} \mathrm{Ru}$ & $39.35 \pm 0.05$ days & $49.71(86.4 \%), 610.3(5.4 \%)$ \\
\hline${ }^{95} \mathrm{Zr}$ & $63.98 \pm 0.06$ days & $724.2(43.1 \%), 756.7(54.6 \%)$ \\
\hline${ }^{144} \mathrm{Ce}$ & $284.5 \pm 1.0$ days & $\begin{array}{l}696.4(1.34 \%), \quad 1489.2(0.26 \%), \\
2185.6(0.66 \%) \text { gamma rays from } 144 \mathrm{Pr} \\
\left(t_{\frac{1}{2}}=17.3 \mathrm{~m}\right) \text { daughter }\end{array}$ \\
\hline $106_{\mathrm{Ru}}$ & 366.4 days & $\begin{array}{l}622.2(9.8 \%), \quad 1050.5(1.6 \%), \\
1562.2(0.17 \%) \text { gamma rays from } 106_{\mathrm{Rh}} \\
\left(t_{1}=29.8 \mathrm{~s}\right) \text { daughter }\end{array}$ \\
\hline${ }^{134} \mathrm{Cs}$ & $2.062 \pm 0.005 \mathrm{yr}$ & $\begin{array}{l}604.7(97.6 \%), \quad 795.8(85.4 \%) \\
801.8(8.7 \%), \quad 1038.5(1.00 \%) \\
1167.9(1.81 \%), \quad 1365.1(3.04 \%)\end{array}$ \\
\hline${ }^{154} \mathrm{Eu}$ & $8.5+0.5 \mathrm{yr}$ & $\begin{array}{l}996.3(10.3 \%), \\
1274.4(35.5 \%)\end{array}$ \\
\hline $137 \mathrm{Cs}$ & $30.17 \pm 0.03 \mathrm{yr}$ & $\begin{array}{l}661.6(89.9 \%) \text { gamma ray from } 137 \mathrm{~m}_{\mathrm{Ba}} \\
\left(t_{\frac{1}{2}}=2.55 \mathrm{~m}\right) \text { daughter }\end{array}$ \\
\hline
\end{tabular}

a Values in parenthesis are the branching ratio of the specific gamma ray. 
5. Calorimetry. A PWR fuel assembly with 30000 MWD/MTU burnup and $\hat{\varepsilon}$ yr of cooling time generates between 1 and $2 \mathrm{~kW}$ power. ${ }^{22}$ This signature can be measured nondestructively to verify that the assembly contains a heat source, presumably, irradiated fuel materials. Precise measurement of the entire fuel assembly requires a large experimental apparatus, but simpler techniques that measure only the exterior surfaces are being investigated. 23

B. Quantitative or Variable Measurements

Quantitative or variable measurements differ significantly t'rom qualitative or attribute measurements by the level of verification requirad. For quantitative measurements, a specific variable is measured as precisely as possible. This variable is then related to the irradiation exposure of the fuel assembly, i.e., burnup, fissile content. These measurements provide more precise information required for safeguarding irradiated fuel assemblies.

1. HRGS has been widely applied to the characterization of irradiated fuel materials for safeguards. ${ }^{10,11}$ The technique is based on establishing correlations between measured isotopic activities or ratios and operator-declared values. These correlations are then used to verify the operator-declared values. Values that have been verified include cooling times, burnup, and $\mathrm{Pu} / \mathrm{U}$ ratio. 5

Correct interpretation of HRGS results depends on understanding several limitations of the technique. In an LWR fuel assembly, only the outer regions can be examined because inner rods are self-shielded. For example, for the relatively high-energy gama ray of ${ }^{140} \mathrm{La}(1596 \mathrm{keV})$, the intensities of the centermost rods in a $15 \times 15$ PWR fuel assembly are attenuated by a factor of nearly 15 compared to the outer row of rods. ${ }^{16}$ Similar effects have been calculated for other power reactor fuels. 17

Fission products may not be uniformly distributed axially and radially within a fuel assembly. The local (pin-to-pin) power distribution can vary because of the location of burnable poison rods and control rods, their location in the core, and the initial enrichment and configuration of the assembly. Another factor is the possible axial and radial migration of fission products within the individual fuel pins. ${ }^{24}$ Axial migration can adversely affect the results if the entire fuel assembly is not scanned. The radial migration can affect the relative intrinsic efficiency corrections because different isotopes migrate to different radial locations. If an intrinsic efficiency calibration 
is used, then all the isotopes are assumed to be distributed identically within the assembly. These limitations must be recognized in evaluating the accuracy and the usefulness of the spectral data obtained from HRGS.

Figure 5 shows a typical HRGS system in which the fliel assembly is moved vertically past the collimator, and complete spectra (300-2200 keV) are being recorded at specified axial positions. The spectral data are compared with the operator-declared values to establish correlations that can be used to predict burnup from measured parameters. If only one HRGS measurement is obtained, then an integrating function is required to relate the measurement to the entire fuel assembly. Several applicable techniques for obtaining the axial profile were discussed in Sec. III. A.

The kinds of correlations obtainable using HRGS are shown in Figs. $6-8$, where the measured parameters ${ }^{137} \mathrm{cs},{ }^{13 !} \mathrm{Cs} /{ }^{137} \mathrm{Cs}$, and ${ }^{154} \mathrm{Eu} /{ }^{137} \mathrm{Cs}$ are plotted with operator-declared burnup values for a set of 14 PWR assemblies. The data have been corrected for decay since discharge using the operator-declared discharge date. Each plot has the 95\% confidence bounds plotied. For the ${ }^{137} \mathrm{Cs}$ isotope, the average deviation between the regression line and the given burnup values was 5.1\%. For the isotopic ratios ${ }^{134} \mathrm{Cs} /{ }^{137} \mathrm{Cs}$ and ${ }^{154} \mathrm{Eu} /{ }^{137} \mathrm{Cs}$, the average deviations were $6.5 \%$ and $7.8 \%$, respectively. These results were based on single measurements at the centers of the fuel assemblies. By making several measurements along the profile and integrating the data, the average deviations were not appreciably improved. Although we have assumed

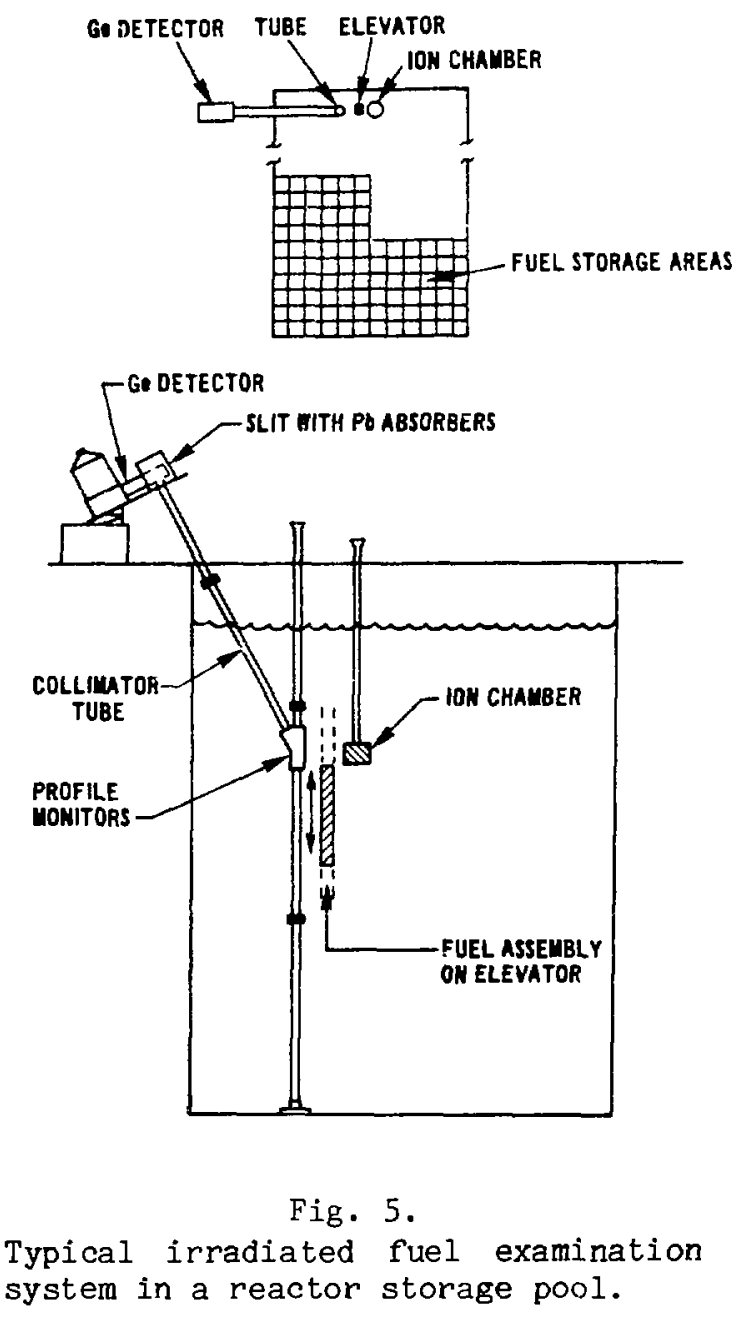


a linear relationship between burnup and the measured parameters, 25 there is some evidence that the relationship can be nonlinear. 9,26

In typical LWR fuel assemblies, precisions in the range of $5-10 \%$ can be obtained for relative burnup values using HRGS. HRGS provides a higher level of verification than the attribute measurements discussed previously. Section IV.C discusses how HRGS, in conjunction with other NDA techniques, can provide a relatively high level of verification of the operator-declared burnup values.

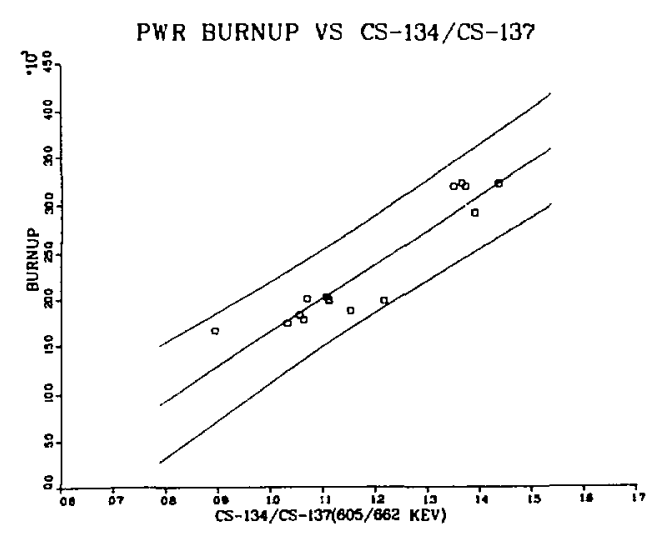

Fig. 7. $134 \mathrm{Cs} / 137 \mathrm{Cs}$ isotopic ratios with respect to operator-declared burnup values with the $95 \%$ confidence bounds and the best fit regression line.

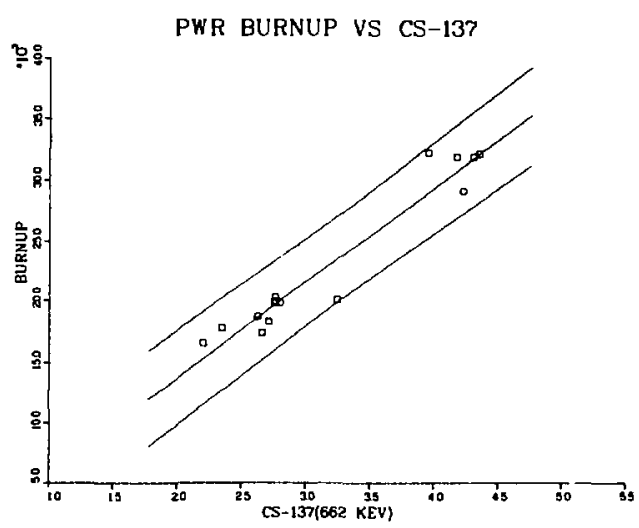

Fig. 6.

$137 \mathrm{Cs}$ activity with respect to operator-declared burnup values with the $95 \%$ confidence bounds and the best fit regression line.

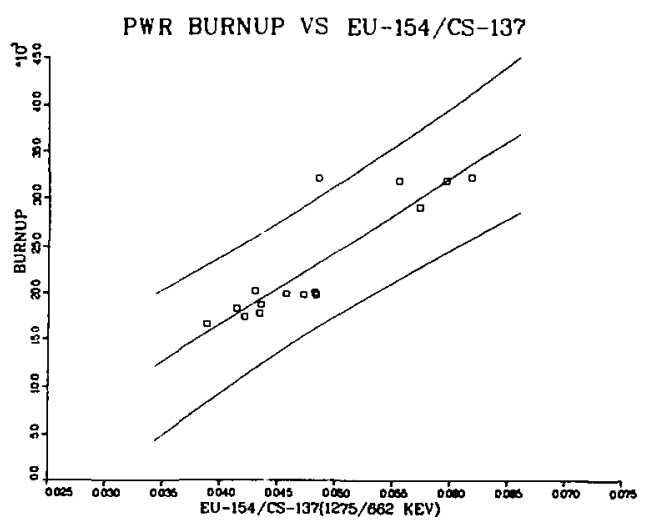

Fig. 8.

$154 \mathrm{Eu} / 137 \mathrm{Cs}$ isotopic ratios with respect to operator-declared burnup values with the $95 \%$ confidence bounds and the best fit regression line. 
2. Passive Neutron Measurements. This technique is particularly attractive for the measurement of spent fuel assemblies for two reasons. One is the high penetrability of neutrons. (Calculations show the interior rods of PWR assemblies contribute nearly the same amount to the total emission rate as the exterior rods. ${ }^{8}$ Therefore the neutron measurement is more sensitive to all the pins in the fuel assembly than is the HRGS measurement.) Second is the relative simplicity of the passive neutron measurement, which only requires a fission chamber, power supply, and a scaler/timer.

The dominant sources of neutrons from the irradiated fuel assemblies are the snontaneous fissioning of the actinide isotopes and the $(\alpha, n)$ reactions on light materials. Also, for very short cooling time (less than a few weeks), the $(\gamma, n)$ reactions can be a significant contributor. The latter source is ignored because, at the Tokai reprocessing facility, fuel assemblies delivered to the plant will have cooling times greater than 120 days.

The principal isotopes that contribute to the neutron yield of irradiated $\mathrm{UO}_{2}$ are listed in Table II. The relative contributions of specific isotopes as a function of cooling time for different burnups are shown in Figs. 9 and 10 for a BWR assembly, ${ }^{9}$ and in Figs. 11 and 12 for a PWR assembly. ${ }^{27}$ The data for these plots were calculated by applying the decay factor to results from destructive analysis.

TABLE II

PRINCIPAL SOURCES OF NEUTRONS IN IRRADIATED UO MATERIALS $^{9}$

Neutrons Produced per gram-second

\begin{tabular}{|c|c|c|c|c|c|}
\hline I sotope & Half-1ives (yr) & $(a, n)$ Reaction & $\begin{array}{c}\text { Spontaneous } \\
\text { Fivision }\end{array}$ & & Total \\
\hline $235 v$ & $7.038 \pm 0.005 \times 10^{8}$ & $7.21 \pm 0.72 \times 10^{-4}$ & $3.86 \pm 0.99 \times 10^{-4}$ & 1.11 & $\pm 0.12 \times 10^{-3}$ \\
\hline $238 \mathrm{v}$ & $4.4683 \pm 0.0024 \times 10^{9}$ & $8.43 \pm 0.84 \times 10^{-5}$ & $1.36 \pm 0.02 \times 10^{-2}$ & 1.36 & $\pm 0.02 \times 10^{-2}$ \\
\hline $238 \mathrm{Pu}$ & $87.71 \pm 0.03$ & $1.56 \pm 0.16 \times 10^{4}$ & $2.60 \pm 0.11 \times 10^{3}$ & 1.82 & $\pm 0.16 \times 10^{4}$ \\
\hline $239 \mathrm{Pu}$ & $2.4131 \pm 0.0016 \times 10^{4}$ & $4.25 \pm 0.43 \times 10^{1}$ & & 4.25 & $\pm 0.43 \times 10^{1}$ \\
\hline $240 \mathrm{Pu}$ & $6.570 \pm 0.006 \times 10^{3}$ & $1.56 \pm 0.16 \times 10^{2}$ & $8.85 \pm 0.10 \times 10^{2}$ & 1.04 & $\pm 0.19 \times 10^{3}$ \\
\hline $242 \mathrm{Pu}$ & $3.763 \pm 0.009 \times 10^{5}$ & $2.27 \pm 0.23$ & $1.743 \pm 0.015 \times 10^{3}$ & 1.743 & $\pm 0.015 \times 10^{3}$ \\
\hline $241_{A m}$ & $432.0 \pm 0.2$ & $3.17 \pm 0.32 \times 10^{3}$ & & 3.17 & $\pm 0.32 \times 10^{3}$ \\
\hline $242 \mathrm{Cm}$ & $0.4456 \pm 0.0001$ & $4.48 \pm 0.45 \times 10^{6}$ & $2.25 \pm 0.08 \times 10^{7}$ & 2.70 & $\pm 0.09 \times 10^{7}$ \\
\hline${ }^{244} \mathrm{Cm}$ & $18.099 \pm 0.015$ & $8.82 \pm 0.88 \times 10^{4}$ & $1.081 \pm 0.007 \times 10^{7}$ & 1.090 & $\pm 0.007 \times 10^{7}$ \\
\hline
\end{tabular}




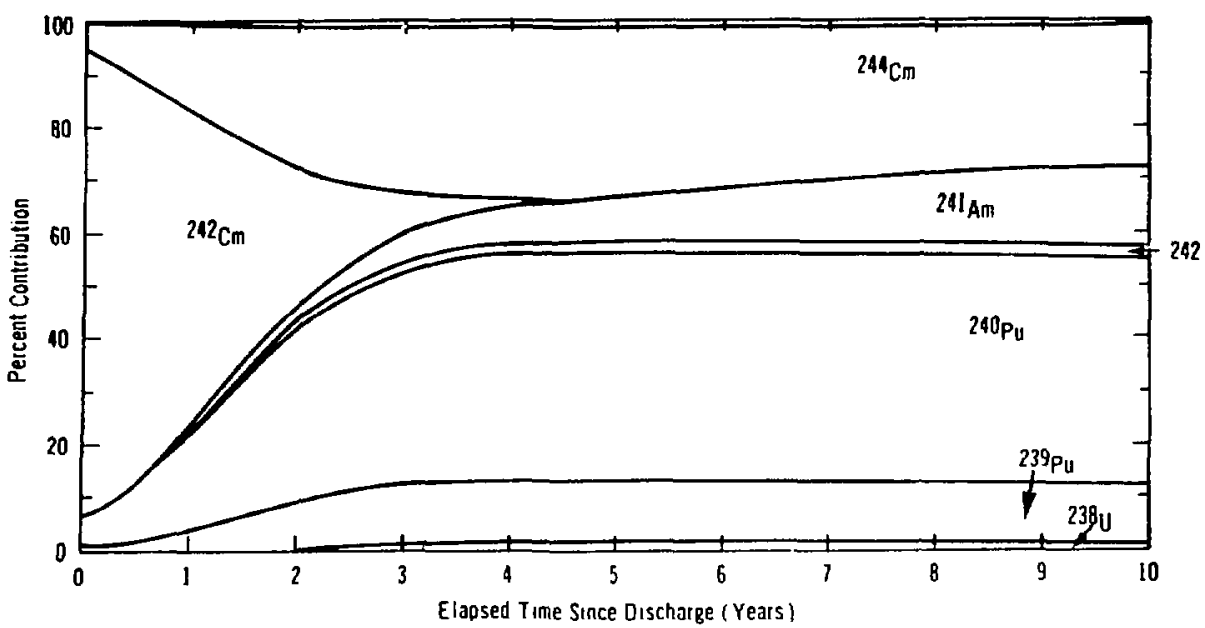

Fig. 9 .

Relative percent contribution to the total neutron rate by specific actinide isotopes for a BWR assembly with 7400 MWD/MTU burnup.

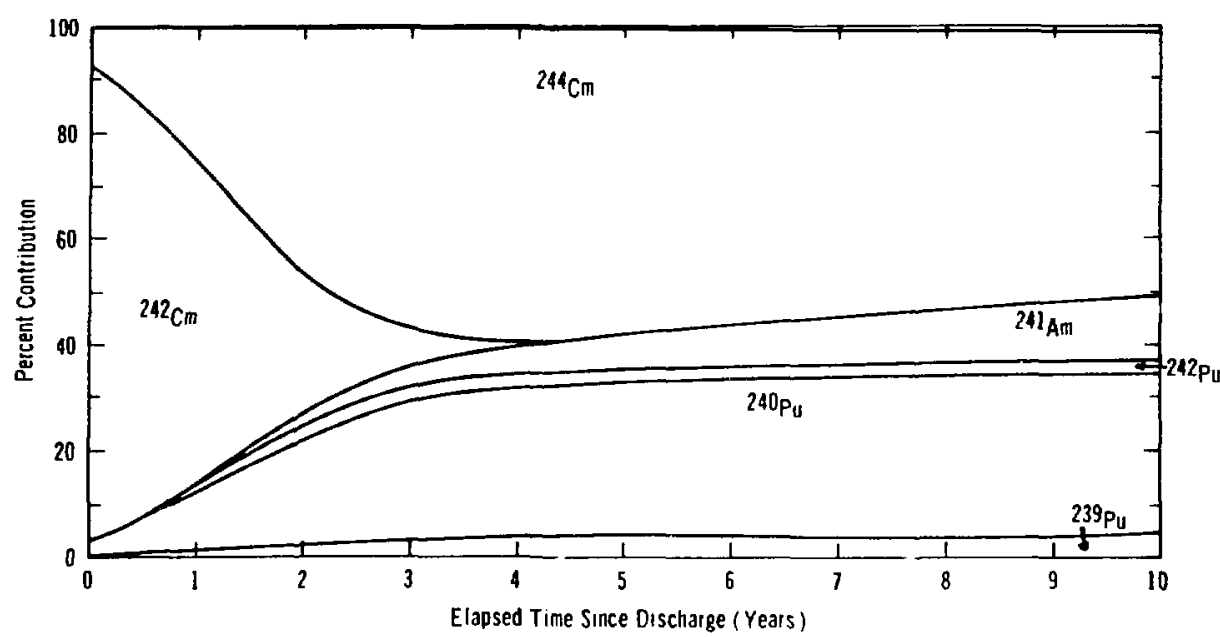

Fig. 10.

Relative percent contribution to the total neutron rate by specific actinide isotopes for a BWR assembly with 11450 MWD/MTU burnup. 


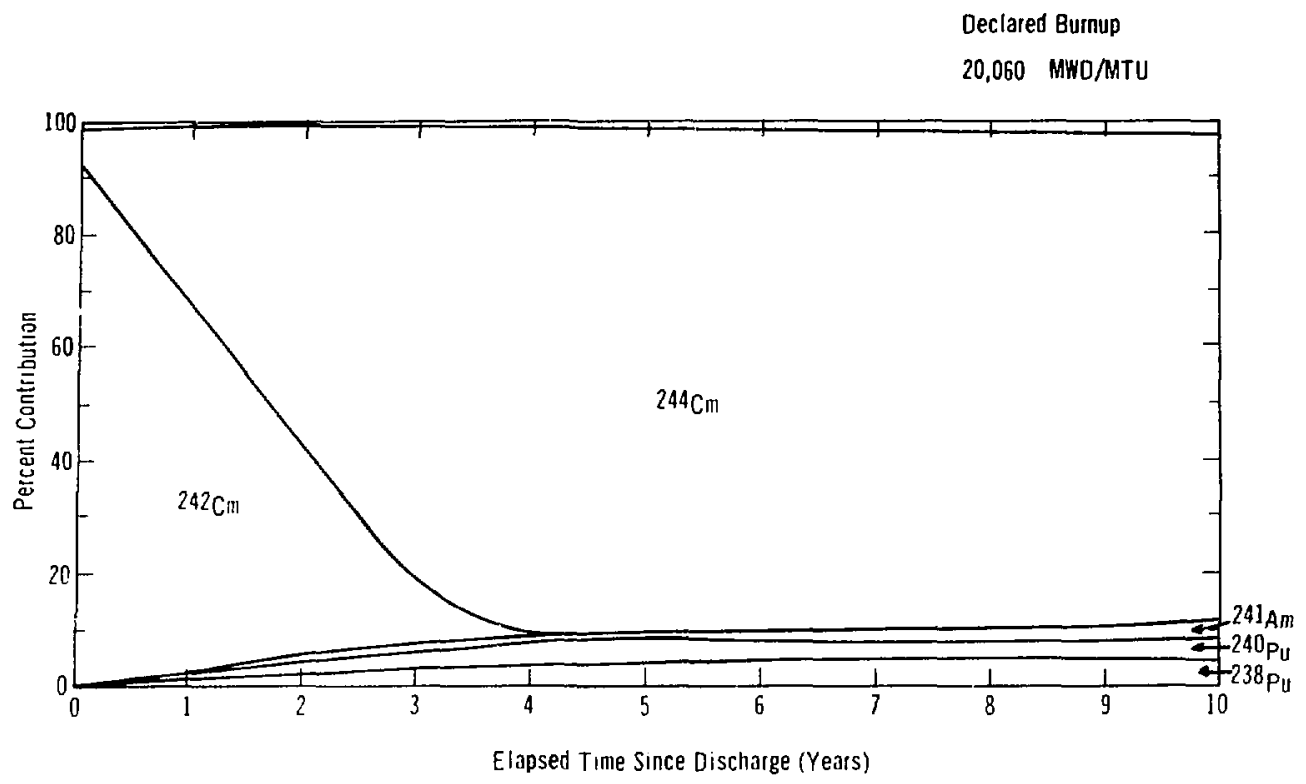

Fig. 11.

Relative percent contribution to the total neutron rate by specific actinide isotopes for a PWR assembly with $20060 \mathrm{MWD} / \mathrm{MTU}$ burnup.

Decjared Burnup

25,095 MWD / MTU

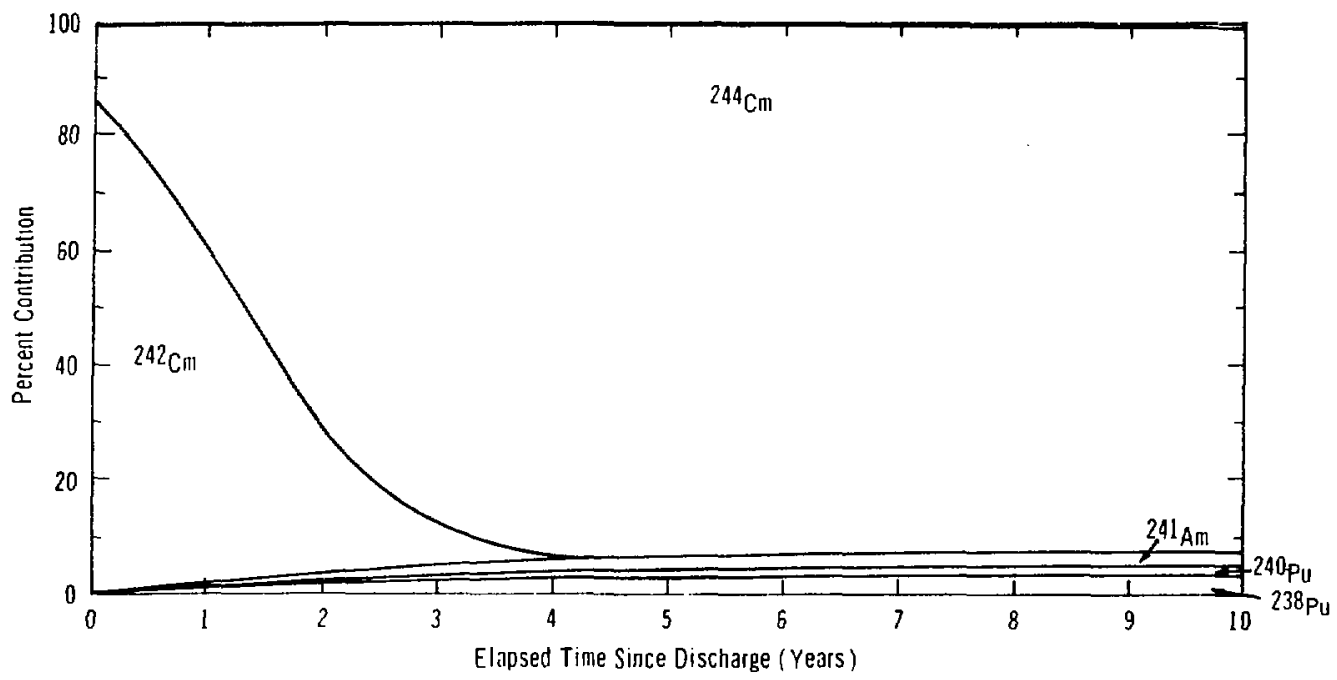

Fig. 12 .

Relative percent contribution to the total neutron rate by specific actinide isotopes for a PWR assembly with 25095 MWD/MTU burnup. 
All four plots show that for cooling times up to $3-4 \mathrm{yr},{ }^{242} \mathrm{Cm}$ (halflife $=163$ days) contributes significantly to the total neutron emission rate. For longer cooling times, ${ }^{244} \mathrm{Cm}$ and $240 \mathrm{Pu}$ become the dominant contributors. The amount of ${ }^{242} \mathrm{Cm}$ in the irradiated fuel is a sensitive function of the irradiation history, with the ${ }^{241} \mathrm{Pu}$ isotope being the critical precursor. Direct measurement of the fissile content of fuel assemblies is not possible using passive neutron techniques. One must infer the fissile content from experimental correlations of passive neutron measurements or calculational techniques.

If the neutron yield for a particular type of fuel assembly is empirically determined to be a power function of burnup, then the relative burnup values of individual assemblies can be determined using the established relationship. If the inferred burnup is consistent with the declared value for that assembly, the $\mathrm{U}, \mathrm{Pu}$ content could be given by computer models that calculate these numbers using the operating history as input.

There are two major experimental problems with this approach. First, an absolute measurement is required. Second, the half-life correction is difficult because the relative concentration of ${ }^{242} \mathrm{Cm}$ is not known. There are approximate methods that may be used to circumvent these problems. It may be possible to calibrate the detector system using well-characterized "calibration assemblies," and the half-life correction may be omitted if the ${ }^{242} \mathrm{Cm}$ contribution to the activity is negligible compared to the balance of the activity. Calculations show that for a PWR assembly, the ${ }^{242} \mathrm{Cm}$ contribution is 5\% after slightly more than $3 \mathrm{yr}$ if the burnup is 8000-10 000 MWD/MTU, or

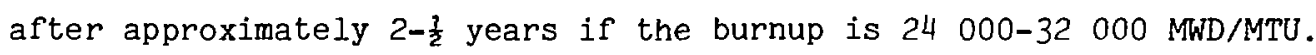

- Data from examinations of 36 PWR fuel assemblies are shown in Table III. These data fall into six basic groups, according to cooling times of 4 to 40 months. The burnup values within each group are similar and the values for different grcups range from approximately 18 000-38 000 MWD/MTU. The uncertainty in the measurements $(15-20 \%)$ is greater than the statistical uncertainty, probably because of the difficulty of positioning the detector accurately with respect to the fuel assembly. In water, a $1-\mathrm{cm}$ positioning error can translate into an error of $10 \%$ in the relative counting rate. 
TABLE III

RELATIVE NEUTRON RATES FOR PWR ISSEMBLIES

Fuel Assembly

A37P

A38P

A39P

A49P

A59R

A58R

A57R

A45R

A 46R

A 47R

A48R

$\mathrm{B} 60 \mathrm{R}$

$\mathrm{B} 61 \mathrm{R}$

$\mathrm{B} 62 \mathrm{R}$

$B 63 R$

B50R

B51R

B49R

B48R

B47R

B07P

B19P

B31P

B43P

B55P

C55R

C57R

C58R

C5. $\mathrm{R}$

C47R

C48R

C03P

Cl5P

C39P

C51P

C63P
Operator-Declared

Burnup (MWD/MTU) $\quad$ Cooling Time (months)

19174

18845

18932

18813

19619

19941

19723

19728

19956

20010

20223

31280

30551

30546

31080

30836

30668

29875

27876

30571

26852

30665

29699

30675

31070

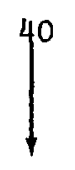

532

762

647

498

781

1078

717

661

694

832

683

$22 \quad 3381$

2727

2648

2676

2322

2876

2295

2091

2612

2183

3054

2404

2487

2618

36278

33530

33764

33192

33917

35055

$39 n 25$

38694

35086

38860

32564
17

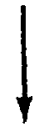

10

1

1
4929

3263

4133

3273

3287

4130

9132

8110

6773

7427

5026 
Note that the data as plotted in Fig. 13 appear (with the exception of the 4-month cooling time) to follow the empirical relationship

Count rate $=\alpha *(\text { Burnup })^{\beta}$

The data have not been corrected for cooling time. The fact that the short cooling time data do not follow this relationship is more clearly shown in Fig. 14, which is a linear plot of the same data and functional relationship (different weights are used in the fits). This same functional relationship has been observed several times. 8,28

It should not be inferred that the slope ( $\beta$ ) of the line is a fundamental constant. In fact, the effect of cooling time on $\beta$ is iilustrated in Fig. 15, where the relative neutron activity as a function of burnup is plotted for various cooling times for a PWR assembly. $27 \quad \beta$ increases from 2.5 to 3.9 as cooling times increase from 0 to $10 \mathrm{yr}$.

For a generic type of reactor fuel, one may be abie to define regions of burnup and cooling time, over which the normalized data would follow the above relationship. Although this is a consistency check, it may be possible to calibrate the counting system, e.g., against a well-characterized assembly, to determine empirically the burnup of the assembly.

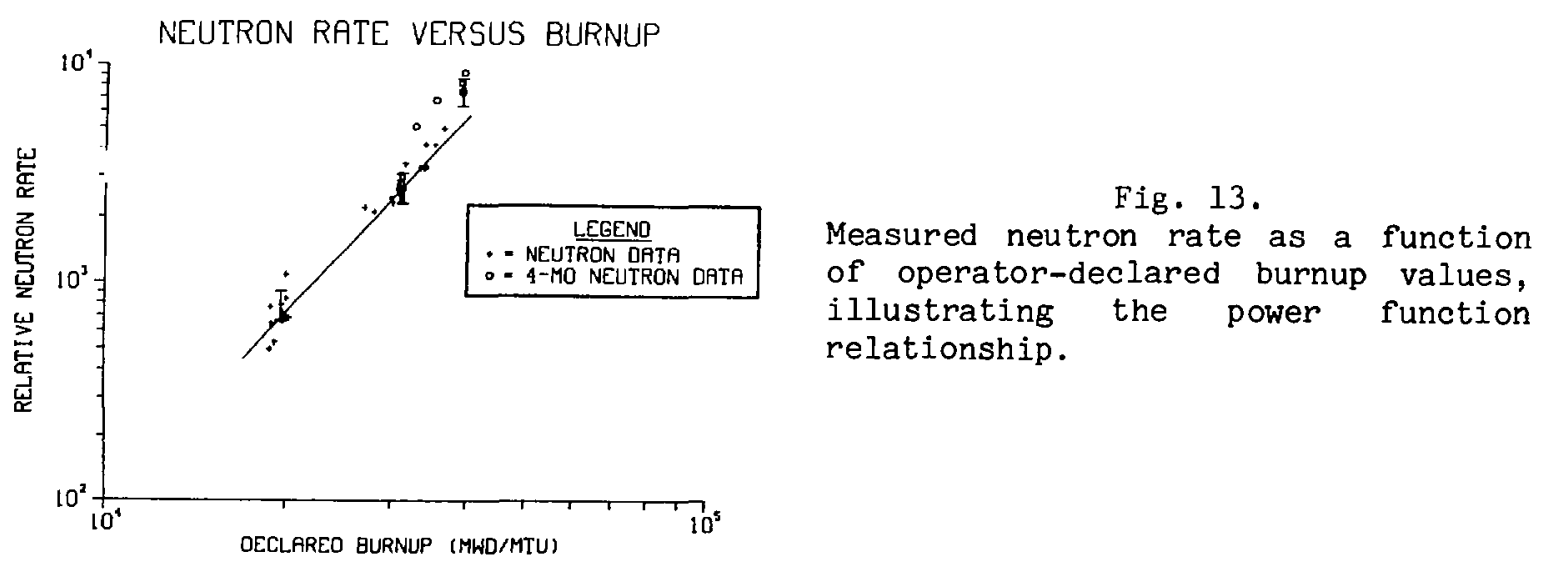




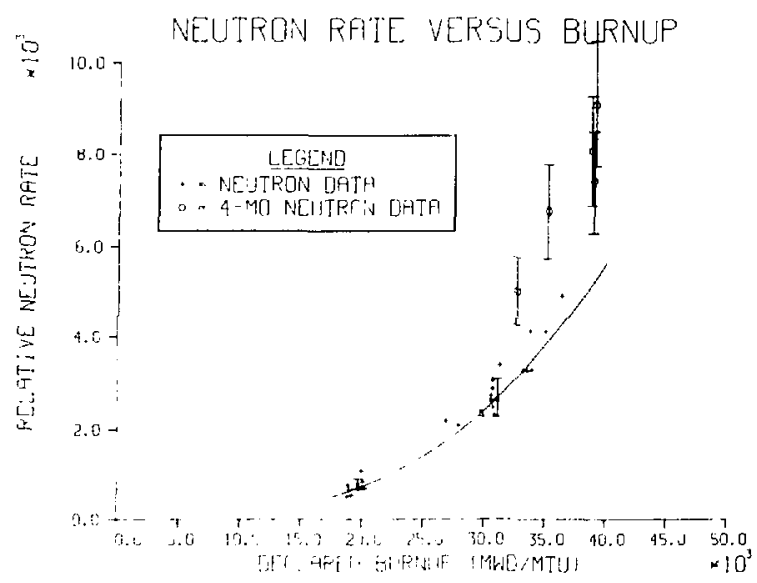

Fig. 14.

Measured neutron rate vs declared burnup values with outlying values of the fuel assemblies with 4 -month cooling times.

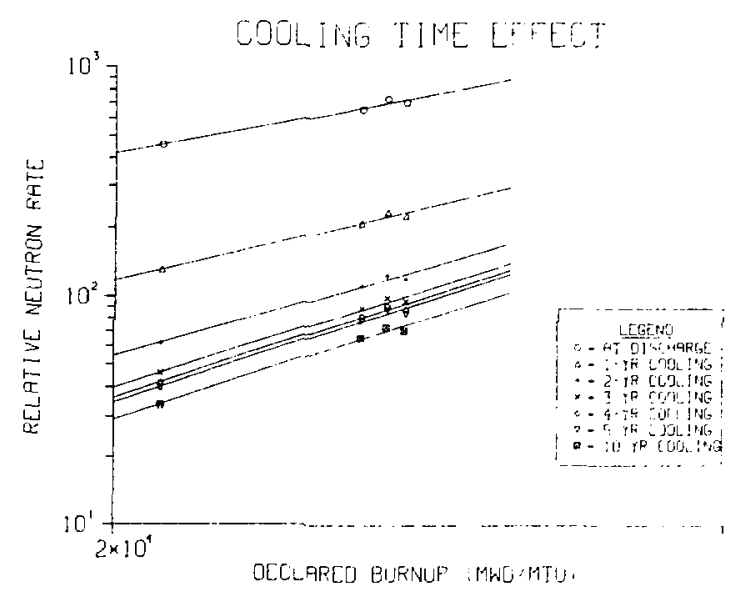

Fig. 15.

Neutron count rate vs declared burnup for various cooling times for a PWR fuel assembly.

Applying passive neutron techniques to BWR assemblies poses further problems. For a typical PWR assembly the burnup profile is quite uniform, but the profile of a typical BWR assembly can vary because of the control rods and the variable void fraction in the boiling region. Therefore, normalizing the neutron measurement to the entire length, becomes more difficult.

3. Coincidence Neutron Technique. The primary difficulty in interpreting the passive neutron signal is that ${ }^{242} \mathrm{Cm}$ has a short half-life (163 days) and a complicated production history. A technique to separate the ${ }^{242} \mathrm{Cm}$ component in the neutron measurement was recently suggested by $H$. Menlove, 29 using an autocorrelation coincidence method. 30,31

Typical burnup histories $\geqslant 20000$ MWD/MTU) show the major sources of neutron emission to be ${ }^{242} \mathrm{Cm}$ and ${ }^{244} \mathrm{Cm}$ for the first few years after the fuel assemblies are removed from the reactor, and ${ }^{244} \mathrm{~cm}$ thereafter. Table II shows interesting differences between these two isotopes with respect to their spontaneous fission (SF) and $(\alpha, n)$ neutron contributions. The isotope ${ }^{244} \mathrm{Cm}$ has a much higher SF fraction than ${ }^{242} \mathrm{Cm}$. The ratio of $\mathrm{SF} /(\alpha, n)$ is 123 for ${ }^{244} \mathrm{Cm}$ as compared to a ratio of 5 for ${ }^{242} \mathrm{~cm}$, which translates to a discrimination ratio 31 of $123 / 5$, or 24 , whisis is more than adequate for separation of the two isotopes. 
The proposed technique uses an in-pool cylindrical neutron detector (fission chambers or ${ }^{10} \mathrm{~B}$ tubes) to count the single (not time-correlated) and coincidence neutron rates from the fuel assembly. Because the $(\alpha, n)$ neutrons give only single counts and the SF neutrons can be time-correlated, the coincidence counting method can be used to separate the two components.

For fuel assemblies with low burnup, ${ }^{240} \mathrm{Pu}$ is a major component with an $\mathrm{SF} /(\alpha, n)$ ratio of 5.7 , so it should behave similarly to ${ }^{242} \mathrm{Cm}$ in the separation. This presents a problem for short cooling times, but after 3 yr cooling time, the ${ }^{242} \mathrm{~cm}$ has decayed away and the coincidence technique might be used to directly verify the relative plutonium content.

4. Active Neutron Technique. Active neutron interrogation of LWR fuel assemblies has been under investigation for some time 5,32 and has been applied to selected fuel assemblies. ${ }^{33}$ This technique has the advantage of directly measuring the fissile content of the assembly without establishing a correlation between an indirect parameter and the fissile content. Application of these techniques should yield results with precision of at least $5 \%$, but the size and economics of the required experimental setup limit the application of the method at the present time.

\section{DISCUSSION}

\section{A. Levels of Verification}

The level of safeguards verification of irradiated fuel assemblies depends on the types and number of measurements performed. A direct quantitative measurement of the uranium and plutonium isotopes is the highest level of verification. Available nondestructive techniques cannot provide this level of verification; most techniques are more qualitative in nature. HRGS is generally accepted as the best available technique, but it only measures an indirect signature of the fissile content and has several limitations, as discussed in Sec. III.B.I.

The characteristics of an irradiated fuel assembly can be stated as follows.

(a) It looks like a fuel assembly, with the correct color and identification number.

(b) It is highly radioactive and contains fission products.

(c) Neutrons are emitted by the assembly.

(d) Its activity profile is similar to that of other assemblies of the same type. 
The confidence level of verification increases with the number of characteristics measured. At present, the highest level of confidence is achieved by combining HRGS with neutron and gamma profile measurements. This verifies the presence of the relative fission product inventory, the presence of fissionable material, and the integrity of gamma activity along the length of the assembly. The next lower confidence level is a combination of any two measurements, HRGS and neutron, neutron and profile, or HRGS and profile. A still lower confidence level is achieved by a single measurement, ARGS, neutron, or profile.

Selection of the appropriate level of verification must be based on linitations of the facility, manpower and instrumentation, and impact upon the normal operations.

\section{B. Sampling Strategy}

Sampling strategy is an essential element of the verification procedure and must be based on available techniques. The strategy must provide timely information with the required confidence level. As discussed in Sec. I, the two measurement methods are (1: qualitative or attribute measurements, and (2) quantitative or variable measurements. ${ }^{34}$ The qualitative or attribute measurement quickly checks individual assemblies for medium to large defects with a high degree of certainty. Quantitative or variable measurements are more accurate and can detect smaller differences.

As the individual fuel assemblies are unloaded from the shipping cask they should be measured to varify the operator-declared values of exposure. This is a key measurement point in MBA-l to resolve shipper-receiver differences, to establish the change in the pond inventory, and to verify the fuel cycle up to the reprocessing facility. These examinations consist of attribute and variabie measurement methods, as well as identification of specific assemblies. Gross ganma and neutron signatures establish the presence of irradiated materials in the assembly, and HRGS establishes a burnup level. Measurement of all fuel assemblies during the unloading process not only satisfies the safeEuards verification requirements, but contributes to the safe and efficient operation of the facility.

If the inventory must be reverified after the fuel assemblies have been stored, a statistical sampling plan should be used. Attribute measurements require a sample size that includes, with high probability, at least one gross 
defect. For safeguards, the detection probability is typically set to $95 \%$. An approximate formula based on a hypergeometric distribution is given by 35,36

$$
D P=1-(1-f)^{D} \text {, }
$$

where DP is the desired detection probability, $f$ is the fraction of items that must be sampled, and $D$ is the number of defective items to be detected. If the detection probability is $95 \%$ and $D=2$ for PWR assemblies for a significant quantity (approximately $8 \mathrm{~kg}$ plutonium), then approximately $80 \%$ of the PWR assemblies must be measured for attributes. Similarly, for BWR fuel assemblies, $\bar{D}=5$ and $45 \%$ of the assemblies must be examined.

Computation of the variable sample size is divided into ( 1 ) detection of mediun-sized defects, and (2) detection of bias. The sample size for detection of medium defects is given as 34,37

$$
\left[n=N 1-(0.05)^{1 / r}\right]
$$

for $95 \%$ probability of detection. $N$ is the number of fuel assemblies in the sample population; $r$ is the ratio of $M / \gamma \bar{x}$, where $M$ is the significant quantity (approximately $8 \mathrm{~kg}$ plutonium) and $\gamma \bar{x}$ is the fractional size of the defect in each assembly. $r$ is the number of fractional falsification of size $\gamma \overrightarrow{\mathbf{x}}$ needed to accumulate the quantity $M$. If we assume that $\gamma=0.05$ (that is, $5 \%$ of the assembly was removed as a result of a diversion), and that $\mathrm{N}=300$ PWR assemblies, then 11 PWR assemblies must be measured. Similarly, about 27 BWR assemblies must be measured. This assumes that the measurement techniques can detect a $5 \%$ change in declared values.

The sample size calculation for detection over the whole material balance of a bias of size $M$ is much more complicated and will not be presented. The detection probability of a bias is much higher in the analysis of dissolver solutions because most nondestructive techniques are not precise enough. References 34 and 37 have detailed discussions of the computations.

Sample strategies used depend on the type of measurements to be performed. In general, attribute measurements require a larger sample size than variable measurements to verify the declared inventory. The simplified equations presented, in conjunction with time limits imposed, can be used as guidelines in selecting an appropriate sample size and strategy. 


\section{Implementation of NDA Measurement System}

A typical safeguards measurement system could consist of HRGS, neutron detectors, and a gross gamma activity profile monitor. A schematic of such a system is shown in Fig. 16, in which the profile monitor, multielement ion chamber, and HRGS collimator system are attached to the wall of the unloading pool to minimize the required measurement area. The entire system would extend a maximum of $15 \mathrm{~cm}$ into the working space of the unloading pool. At least tinree neutron detectors (probably ${ }^{235} \mathrm{U}$ fission chambers) would be located along the principal axis of the assembly. A fixture would be required for the operator to place the assembly into or against to ensure the correct positioning of the assembly. As discussed previously, the source-to-detector distance is very important in the neutron measurements. Three neuiron detectors are suggested to allow the verification of neutron emitters at several axial positions. Analysis time using multidetectors is the same as for a single detector, and no fuel assembly scanning is required.

This system would provide information about the irradiation history of the assembly from the HRGS, would

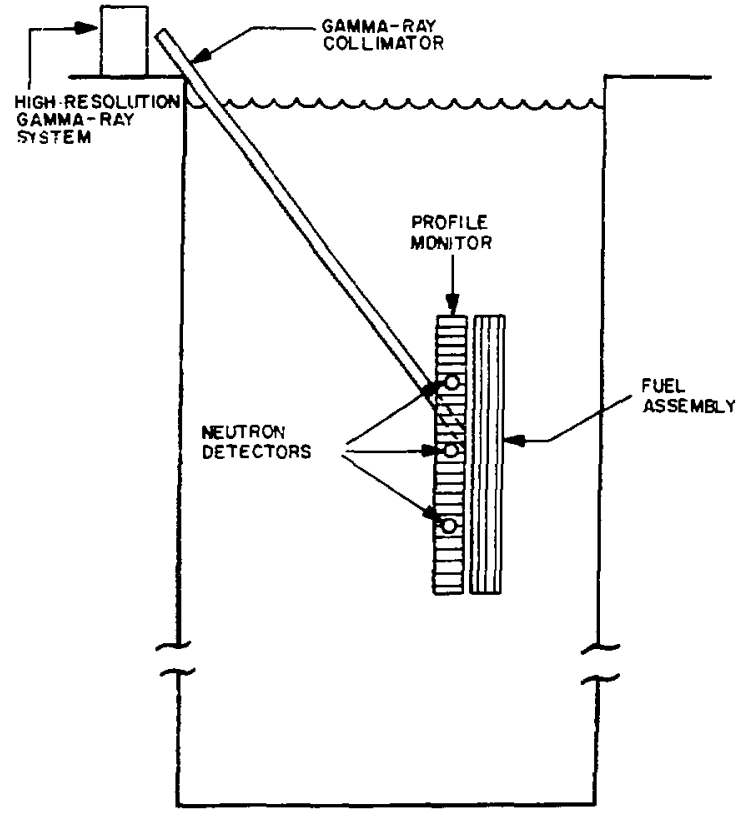

Fig. 16.

Proposed irradiated fuel examination system. verify the presence of neutrons, and would give a gamma activity profile. Each measurement gives information about a separate characteristic, which can be related to similar fuel assemblies for measuring the consistency of the set. Combination of the three measurements establishes a greater confidence level than that of any individual measurement.

Also, the effect on the operations in the spent fuel storage area would be minimal. As the fuel assemblies are unloaded from the cask, each assembly can be placed in the fixture of the detection system. Because there is no physical scanning, the fuel handling tool can 
remain attached to the assembly. After the specified counting period (probably less than $15 \mathrm{~min})$, the assembly can be placed in the storage container, as is the present procedure. This system does not require removal of the assemblies from the storage containers, therefore the fuel assemblies in the storage pool can be remeasured as required to ensure the fissile inventory.

\section{ACKNOWLEDGMENTS}

Many of the conclusions in the report were based upon the work performed by the various safeguards groups at the Los Alamos Scientific Laboratory.

\section{APPENDIX}

\section{CALCULATION OF BURNUP IN SPENT FUEL ASSEMBLIES}

Fuel assemblies that are removed from reactor cores and placed in spent fuel storage facilities must have declared burnup values. Development of techniques to measure burnup depends greatiy on the accuracies of these operatordeclared values. In general, data from a variety of spent fuel assemblies are gathered and correlated to operator-declared values to establish models.

For gamma-ray measurements, isotopic ratios are generally related to declared burnup values by the relationship

$$
B U=A \cdot R_{1}+B \text {, }
$$

where $R_{1}$ is a measured ratio, and $A$ and $B$ are experimentally determined constants. Similarly, the empirical model

$$
\mathrm{BU} \propto \mathrm{CR}^{1 / \beta}
$$

has been applied to neutron measurements of fuel assemblies with similar irradiation histories. $C R$ is the relative neutron emission rate and $B$ is determined experimentally. Once a correlation is established and values for A, B, 
and $\beta$ are known, then the burnup values for individual fuel assemblies can be determined from equations like $(A-I)$ and $(A-2)$.

To establish the validity of models similar to those above, accuracy of operator-declared burnup values is doubly important. First, these correlations and the accuracias of the $A, B$, and $B$ parameters are directly related to accuracy of the declared values, and second, once the parameter values have been established, operator-declared values are verified with empirical results.

Because declared-value accuracy is so important, an effort has been made to examine the origin and accuracy of operator-declared values. Although much of the information about the specific techniques used by operators to determine burnup is reactor vendor proprietary information, enough is available to provide general descriptions of the techniques and to establish some error estimates.

For General Electric (GE) BWRs, declared burnup comes from two sources. The first is from information supplied by on-line process computers (PC) attached to each reactor facility. The PCs continuously monitor reactor operating data and use these data in conjunction with computer models to determine instantaneous core operating parameters such as nodal bundle power, nodal peak heat flux, and critical heat flux ratios. During reactor operating cycles, data from local power range monitors (LPRM) are continuously fed directly to the $\mathrm{PC}$, and from these data, more refined axial and radial operating data are calculated. Periodically (at least once a month), more sophisticated axial power data are collected from traveriing incore probes (TIP) and compared to corresponding PC predicted data. Noticeable discrepancies between TIP and PC data (particularly asymmetrics in symmetric core regions) signal possible fuel problems and such discrepancies must be resolved. Because TIP data reflect actual operating conditions, PC data are normalized to the TIP data. Thus PC accumulated data are reasonably accurate ${ }^{38-40}$ and closely predict operating conditions over the reactor cycle. Burnup associated with individual fuel assemblies is determined from the PC data for power extracted from the assembly. Uncertainties in the declared burnup numbers, which are estimated from knowledge of errors associated with PC data, are fuel assembly integral, 4\%, and nodal (6 in.) axial distribution, 6\%. These uncertainties have not been verified experimentally. 
A three-dimensional BWR Core Simulator code 41,42 is the second method for determining fuel assembly burnup. PC data from operating BWRs (with GE fuel supply agreements) are sent to GE each month, where they are used in a sophisticated three-dimensional computer code to track core operating performance. Burnup for the individual assemblies is calculated from PC data on core thermal power and electrical power generation. Average burnup for the entire core is allocated throughout the core based on power distributions calculated by the BWR Core Simulator. Because core simulator calculations are continually updated with actual operating data, uncertainties in calculated burnup values are estimated to be on the same order as PC error estimates shown above.

Because BWR operators have access to burnup values obtained from both methods, either number could be associated with an assembly in a spent fuel storage facility. However, both methods use the same operating data and have similar error uncertainties, so burnup values from either should be well within the stated statistical error.

Less information is available on techniques used to determine burnup in PWR fuel assemblies. In general, as with BWRs, burnup in PWRs is determined from data obtained monthly from in-core flux monitors. Data from these monitors are used in a computer code to track various operating parameters such as axial and radial flux distributions. Then, design prediction parameters supplied by the vendor are used to normalize flux distributions to power distributions. From these power distributions over the reactor operating cycle, burnup values for the individual assemblies are determined. Because of the similarities in the methods used to determine burnup in PWR and BWR assemblies, and because PWRs are easier to model analytically, uncertainties associated with declared burnup for PWR assemblies are assumed to be on the same order as those for BWRs. Thus, until more complete data are available, uncertainties in operator-declared burnup values are assumed to be $4-5 \%$ for assembly averaged values, and $6-8 \%$ for axially distributed values. 


\section{REFERENCES}

1. "Tokai Advanced Safeguards Technology Exercise (TASTEX)," Program Plan, International Safeguards Project office, Brookhaven National Laboratory, Upton, New York, May 15, 1978.

2. K. Nakejima, T. Koizumi, T. Yamavouchi, S. Watanabe, and N. Suyama, "Development and Demonstration of Safeguards Techniques in the Tokai Fuel Reprocessing Plant," IAEA-SM-231/34, Int. Symp. on Nuclear Mat. Safeguards, Vienna, Austria, October 2-6, 1978.

3. K. Ikawa, H. Ihara, H. Sakuraji, H. Nishimura, and M. Hirata, "Study of the Application of DYMAC Principles to Safeguarding Spent Fuel Reprocessing Plants," Japan Atomic Energy Research Institute report JAERI Memo 8241 (April 1979).

4. J. P. Holmes and C. P. Cameron, "Investigation of the Feasibility of Applying an Integrated Containment and Surveillance System in the Spent Fuel Receiving Areas of the PNC, Tokai Nuclear Fuel Recprocessing Facility," Sandia Laboratories report SAND 78-1740 (August 1978).

5. Advisory Group Meeting on the Nondestructive Analysis of Irradiated Power Reactor Fuel, IAEA report AG-11, Vienna, Austria, April 4-7, 1977.

6. E. J. Dowdy and J. T. Caldwell, Eds., "Irradiated Fuel Monitors. Preliminary Feasibility Study," Los Alamos Scientific Laboratory report LA-7699 (ISPO 51) (May 1979).

7. D. M. Lee, J. R. Phillips, S. T. Hsue, K. Kaieda, J. K. Halbig, E. G. Medina, and C. R. Hatcher, "A New Approach to the Examination of LWR Irradiated Fuel Assemblies Using Simple Gas Chamber Techniques," Los Alamos Scientific Laboratory report LA-7655-MS (ISPO 48) (March 1979).

8. S. T. Hsue, J. E. Stewart, K. Kaieda, J. K. Halbig, J. R. Phillips, D. M. Lee, and C. R. Hatcher, "Passive Neutron Assay of Irradiated Nuclear Fuels," Los Alamos Scientific Laborc,ory report LA-7645-MS (ISPO 43) (February 1979).

3. J. R. Phillips, D. M. Lee, T. R. Bement, J. K. Halbig, S. T. Hsue, and K. Kaieda, "Nondestructive Examination of Irradiated LWR Fuel Assemblies," Proc. INM 20th Annual Meeting, Albuquerque, New Mexico, July 16-19, 1979.

10. T. Dragnev, "Nondestructive Assay Techniques for Nuclear Safeguards Measurements," in Atomic Energy Review, Vol. 11, No. 2, 1973.

11. S. T. Hsue, T. W. Crane, W. L. Talbert, Jr., and J. C. Lee, "Nondestructive Assay Methods for Irradiated Nuclear Fuels," Los Alamos Scientific Laboratory report LA-6923 (January 1978).

12. S. Matsuura (JAERI) and K. Yokoyama (PNC), private communication (1978).

13. H. O. Menlove, Los Alamos Scientific Laboratory, private communication (1978). 
14. H. H. Davis, T. P. Papazoglou, and L. J. Ferrell, "Poolside Examination of PWR Demonstration Fuel Assemblies and Creep Specimens--End of Cycle," Babcock and Wilcox report LRC 4733-3 (May 1977).

15. R. Gold, F. H. Ruddy, E. P. Lippincott, W. N. McElroy, and J. H. Roberts, "Spent Thermal Reactor Fuel Assembly Characterization with Solid State Track Recorders," Hanford Engineering Development Laboratory report HEDL-TME 78-89 UC-796.

16. G. R. Parkos and G. F. Valby, "Gamma Scan Measurements at Zion Station Unit 2 Following Cycle 1," Electric Power Research Institute report EPRI NP-509 (October 1977).

17. M. B. Cutrone and G. F. Valby, "Gamma Scan Measurements at Quad Cities Nuclear Power Station Unit 1 Foliowing Cycle 2," Electric Power Research Institute report EPRI NP-214 (July 1976).

18. D. M. Lee, J. R. Phillips, S. T. Hsue, K. Kaieda, J. K. Haibig, E. G. Medina, and C. R. Hatcher, "A Quick and Accurate Pr file Monitor for Irradiated Fuel," Proc. 1st ESARDA Symp. on Safeguards and Nucl. Mat. Management, pp. 265-269, Mol, Belgium, April 25 and 26, 1978.

19. C. M. Lederer and V. S. Shirley, Eds., Table of Isotopes - Seventh Edition (John Wiley and Sons, Inc., New York, 1978).

20. Nuclear Data Sheets 15, 203 (1975).

21. Nuclear Data Sheets $\underline{13}, 337$ (1974).

22. E. Voiland, private communication, G.E. Morris Operation Spent Fuel Storage Facility (August 1979).

23. R. Davis, private communication, Hanford Engineering Development Laboratory (May 1978).

24. N. Beyer, M. deCarolis, E. Dermendjiev, A. Keddar, and D. Rundquist, "IAEA NDA Measurements as Applied to Irradiated Fuel Assemblies," IAEA-SM 231/106

- Int. Symp. Nucl. Mat. Safeguards, Vienna, October 2-6, 1978.

25. D. E. Christensen, "Collection and Analysis of Measured Fission Product Data," U.S. Arms Control and Disarmament report (March 1979).

26. T. Suzaki, H. Tsuruta, and S. Matsuura, "Non-Destructive Gamma-Ray Spectrometry and Analysis on Spent Fuel Assemblies of the HPDR-1 Core," Japan Atomic Energy Research Institute report JAERI Memo 8164 (March 1979).

27. P. Barbera, G. Bidoglio, M. Bresesti, R. Chevalier, et al., "Post-Irradiation Examination of the Fuel Discharged from the Trino Vercellese Reactor after the 2nd Irradiation Cycle," Commission of European Communities report EUR 5605.e (1976).

28. E. Dermendjiev, private communication, International Atomic Energy Agency (1978). 
28. H. O. Menlove, private communication, Los Alamos Scientific Laboratory, June 15, 1979.

29. Merlyn S. Krick and Howard O. Menlove, "The High-Level Neutron Coincidence Counter (HLNCC): Users' Manual," Los Alamos Scientific Laboratory report LA-7779-M (June 1979).

30. H. O. Menlove, R. H. Augustson, and Darryl B. Smith, "A Multi-Spectra Neutron Irradiation Technique for th: NDA of Fissionable Materials," Nucl. Technol. 10, 366 (1971).

31. N. Ensslin, M. L. Evans, H. O. Menlove, and J. E. Swansen, "Neutron Coincidence Counters for Plutonium Measurements," J. Institute Nuclear Materials Management, Vol. VII, No. 2, Summer 1978.

32. T. Gozani, "Active Direct Measurement of Residual Fissile Content in Spent Fuel Assemblies," Electric Power Research Institute report EPRI 278-1 (1975).

33. H. Wuerz, private communication, Institut fur Neutronenphysik und Reacktortechnik (August 1979).

34. C. G. Hough and T. M. Beetle, "Statistical Methods for the Planning of Inspections," Proc. Symp. on Safeguarding Nuclear Materials, Vol. I, pp. 561-579, October 20-24, 1975, Vienna.

35. D. D. Cobb, J. L. Sapir, E. A. Kern, and R. J. Dietz, "Concepts for Inventory Verification in Critical Facilities," Los Alamos Scientific Laboratory report LA-7315 (December 1978).

36. D. D. Cobb, H. A. Dayem, and R. J. Dietz, "Preliminary Concepts: Safeguards for Spent Light-Water Reactor Fuels," Los Alamos Scientific Laboratory report LA-7730-MS (1979).

37. C. G. Hough, R. A. Schneider, K. B. Stewart, J. L. Jaech, and C. A. Bennett, "Example of Verification and Acceptance of Operator Data LowEnriched Uranium Fabrication," Battelle North West Laboratory report BNWL1852 (August 1.974).

33. J. F. Carew, "Process Computer Performance Evaluation Accuracy," General Electric Company report NEDO-20340, 74NED32, Class I (June 1974).

39. J. F. Carew, "Process Computer Performance Evaluation Accuracy Amendment 1," General Electric Company report NEDO-20340-1, Class I (September 1975).

40. J. F. Carew, "Process Computer Performance Evaluation Accuracy Amendment 2," General Electric Company report NEDO-20340-2, Class I (September 1975).

41. J. A. Woolley, "Three-Dimensional BWR Core Simulator," General Electric Company report NEDO-20953, 75NED42, Class I (May 1976).

42. G. R Parkos, "BWR Simulator Methods Verification," General Electric Company report NEDO-20946A, 76́NED23, Class I (January 1977). 